\title{
A Remote Sensor System Based on TDLAS Technique for Ammonia Leakage Monitoring
}

\author{
Hongbin Lu, Chuantao Zheng *, Lei Zhang, Zhiwei Liu, Fang Song, Xiuying Li *, Yu Zhang and Yiding Wang
}

Citation: Lu, H.; Zheng, C.; Zhang, L.; Liu, Z.; Song, F.; Li, X.; Zhang, Y.; Wang, Y. A Remote Sensor System Based on TDLAS Technique for Ammonia Leakage Monitoring. Sensors 2021, 21, 2448. https:// doi.org/10.3390/s21072448

Academic Editor: Krzysztof M. Abramski

Received: 27 January 2021

Accepted: 4 March 2021

Published: 2 April 2021

Publisher's Note: MDPI stays neutral with regard to jurisdictional claims in published maps and institutional affiliations.

Copyright: (c) 2021 by the authors. Licensee MDPI, Basel, Switzerland. This article is an open access article distributed under the terms and conditions of the Creative Commons Attribution (CC BY) license (https:/ / creativecommons.org/licenses/by/ $4.0 /)$.
State Key Laboratory of Integrated Optoelectronics, College of Electronic Science and Engineering, Jilin University, 2699 Qianjin Street, Changchun 130012, China; luhb18@mails.jlu.edu.cn (H.L.); zhang119@mails.jlu.edu.cn (L.Z.); zhiwei18@mails.jlu.edu.cn (Z.L.); songfang16@mails.jlu.edu.cn (F.S.); yuzhang@jlu.edu.cn (Y.Z.); ydwang@jlu.edu.cn (Y.W.)

* Correspondence: zhengchuantao@jlu.edu.cn (C.Z.); xiuying@jlu.edu.cn (X.L.); Tel.: +86-137-5609-0979 (C.Z.)

\begin{abstract}
The development of an efficient, portable, real-time, and high-precision ammonia $\left(\mathrm{NH}_{3}\right)$ remote sensor system is of great significance for environmental protection and citizens' health. We developed a $\mathrm{NH}_{3}$ remote sensor system based on tunable diode laser absorption spectroscopy (TDLAS) technique to measure the $\mathrm{NH}_{3}$ leakage. In order to eliminate the interference of water vapor on $\mathrm{NH}_{3}$ detection, the wavelength-locked wavelength modulation spectroscopy technique was adopted to stabilize the output wavelength of the laser at $6612.7 \mathrm{~cm}^{-1}$, which significantly increased the sampling frequency of the sensor system. To solve the problem in that the light intensity received by the detector keeps changing, the $2 f / 1 f$ signal processing technique was adopted. The practical application results proved that the $2 f / 1 f$ signal processing technique had a satisfactory suppression effect on the signal fluctuation caused by distance changing. Using Allan deviation analysis, we determined the stability and limit of detection (LoD). The system could reach a LoD of $16.6 \mathrm{ppm} \cdot \mathrm{m}$ at an average time of $2.8 \mathrm{~s}$, and a $\mathrm{LoD}$ of $0.5 \mathrm{ppm} \cdot \mathrm{m}$ at an optimum averaging time of $778.4 \mathrm{~s}$. Finally, the measurement result of simulated ammonia leakage verified that the ammonia remote sensor system could meet the need for ammonia leakage detection in the industrial production process.
\end{abstract}

Keywords: tunable diode laser absorption spectroscopy; wavelength modulation spectroscopy; $2 f / 1 f$ signal processing technique; wavelength-locked; remote sensor

\section{Introduction}

With the continuous development of industrialization, the application of ammonia $\left(\mathrm{NH}_{3}\right)$ in industry has become more and more common, especially in the petrochemical industry, cold chain logistics, and fertilizer production. At the same time, traditional animal husbandry and agriculture are also important sources of ammonia emissions. $\mathrm{SO}_{2}$ and $\mathrm{NO}_{2}$ in the atmosphere react with $\mathrm{NH}_{3}$ under the action of water vapor to produce ammonium sulfate and ammonium nitrate particles. These particles are suspended in the atmosphere to form the PM2.5 aerosol, which is an important reason for the formation of haze $[1,2]$. As a major chemical and agricultural production country around the world, China emits about 13.1 million tons of $\mathrm{NH}_{3}$ into the atmosphere each year, making it the largest $\mathrm{NH}_{3}$ emitter in the world [3]. Therefore, the development of an efficient, convenient, real-time, and high-precision $\mathrm{NH}_{3}$ remote sensor system is of great significance to improve the level of environmental protection and citizens' health.

As a key subject, researchers from various countries have proposed many methods to measure gas concentration [4-12]. As for the remote sensing of ammonia, Force et al. achieved the sensitivity of $5 \mathrm{ppb}$ for atmospheric $\mathrm{NH}_{3}$ measurement by use of a $\mathrm{CO}_{2}$ differential absorption lidar system with the wavelength of $10.716 \mu \mathrm{m}$ and $10.693 \mu \mathrm{m}$ [13]; Theriault et al. designed a compact atmospheric sounding interferometer (CATSI) which could achieve the resolution of $40 \mathrm{ppm} \cdot \mathrm{m}$ for $\mathrm{NH}_{3}$ remote sensing based on differential 
Fourier-transform infrared (FTIR) spectroscopy [14]; Dammers et al. did a lot of work on the research of the spatial distribution of $\mathrm{NH}_{3}$ with mini Differential Optical Absorption Spectroscopy (mini-DOAS) [15-17]. Dror et al. introduced an encoding-decoding method to improve spectral resolution when detecting various chemical species with Raman spectroscopy [18]. Comparing these methods, gas detection systems based on tunable diode laser absorption spectroscopy (TDLAS) technique have the merit of high resolution. However, traditional $\mathrm{NH}_{3}$ detection equipment based on TDLAS is usually deployed with a gas cell inside the device. Furthermore, $\mathrm{NH}_{3}$ will adhere to the pipeline and the system, which affects the accuracy, and the corrosion of pipelines also affects the life of the equipment. [19]. At the same time, the equipment deployed with a gas cell makes the testers inevitably exposed to the environment of $\mathrm{NH}_{3}$ leakage, which is not satisfactory from the perspective of industrial production. With the development of laser and waveguide technology, infrared laser beam can propagate over long distance after collimation. This is also the foundation for infrared laser remote sensing technology to achieve application [20].

In this paper, we propose a remote sensor system for $\mathrm{NH}_{3}$ leakage monitoring in the industrial production process based on the TDLAS technique. This system avoided deploying the gas cell which was usually used in traditional TDLAS sensor system. This change solved the problem caused by the adsorption and corrosion of the ammonia. Combined with the $2 f / 1 f$ wavelength modulation spectroscopy (WMS) technique, this system suppressed the interference caused by the varied intensity and detection distance retained the merit of high resolution of TDLAS gas sensor system. To improve the refresh rate of digital system, we gave up the traditional "triangular wave + sine-wave" WMS scheme and adopted of "wavelength lock" scheme. This change means the system can scan the absorption line of $\mathrm{NH}_{3}$ much more rapidly than the traditional TDLAS gas sensor. To realize the portability, we miniaturized this system into a handheld instrument. Considering the convenience of maintenance, later performance upgrade, and the cost of the system, we developed the digital lock-in amplification and $2 f / 1 f$ signal processing program based on LabVIEW platform. We carried out a series of instrument performance characterization experiments and outdoor practical application tests, which verified the system has satisfactory performance. The $\mathrm{NH}_{3}$ remote sensor system has the advantages of simple structure, low cost, excellent portability, rapid response, remote no-contact measurement, and excellent anti-interference performance, which has promising application prospects.

\section{The Detection Theory and System Structure}

\subsection{2f/1f WMS Signal Processing Technique}

The vibrational absorption spectra of the chemical bonds of gas molecules are located in the mid-infrared band $(2.5-300 \mu \mathrm{m})$. The overtone of these absorption spectra form the near-infrared spectra $(0.78-2.5 \mu \mathrm{m})$ of the gas molecules. Different molecules have their own fingerprint region [21,22]. When the laser beam passes through the measured gas, its light intensity attenuation follows the Lambert-Beer law, which is expressed as:

$$
I(v)=\eta I_{0}(v) \exp [-\alpha(v) L]
$$

when $\alpha(v) L<<1$ (or $\alpha(v) L<0.1)$, the formula is given by:

$$
I \approx \eta I_{0}(v)(1-\alpha(v) L)
$$

where $\eta$ is the reflection index of the target, $I_{0}(v)$ is the intensity of laser output, $I(v)$ is the intensity of signal received by the remote sensor system. $\alpha(v)=P \chi_{\mathrm{NH}_{3}} S_{\mathrm{NH}_{3}} \varphi_{\mathrm{NH}_{3}}$ where $P$ is gas pressure, $\chi_{\mathrm{NH}_{3}}$ is $\mathrm{NH}_{3}$ concentration, $S_{\mathrm{NH}_{3}}$ and $\varphi_{\mathrm{NH}_{3}}$ are the line strength and line shape function of the absorption line, respectively [23].

According to WMS, the laser output wavelength can be modulated by modulating the injection current of the laser. The output frequency of the laser and the intensity are given by [24]:

$$
v(t)=\bar{v}+\operatorname{acos}(\omega t)
$$




$$
I_{0}(t)=\overline{I_{0}}\left(1+i_{1} \cos \left(\omega t+\psi_{1}\right)\right)
$$

where $a$ is the modulation depth, $i_{1}$ is the linear intensity modulation coefficient, and $\psi_{1}$ is the intensity modulation phase shift.

Since the spectral absorption coefficient $\alpha(v)$ is a periodic even function of the modulation frequency $\omega$, it can be expanded in a Fourier cosine series at its central frequency $\bar{v}$ :

$$
-\alpha(\bar{v}+a \cos (\omega t)) L=\sum_{k=0}^{\infty} H_{k}(\bar{v}, a) \cos (k \omega t)
$$

where the $k_{\mathrm{th}}$ Fourier coefficients are given by:

$$
\begin{gathered}
H_{0}(\bar{v}, a)=\frac{P \chi_{N_{H}} L}{2 \pi} \int_{-\pi}^{\pi} \sum S_{N_{3}} \varphi_{N H_{3}}(\bar{v}+a \cos (\omega t)) d \omega t \\
H_{k}(\bar{v}, a)=\frac{P \chi_{N H_{3}} L}{2 \pi} \int_{-\pi}^{\pi} \sum S_{N H_{3}} \varphi_{N_{3}}(\bar{v}+a \cos (\omega t)) \cos (k \omega t) d \omega t
\end{gathered}
$$

From Equations (6) and (7), it can be seen that the amplitude of each harmonic component is proportional to the integral concentration of the measured gas.

During the process of remote sensing, the reflective target is not fixed, and its reflectivity cannot be accurately known either. At the same time, as the remote sensing distance increases, the strength of the signal received by the receiver gradually weakens. In this case, we got the first harmonic and second harmonic by using a lock-in amplifier and normalized the second harmonic with the first harmonic. This is the so-called $2 f / 1 f$ signal processing technique. The influence of changing signal intensity on the detection results can be effectively eliminated in this way. The amplitude of the second harmonic extracted and amplified by the lock-in amplifier can be expressed as $[23,24]$ :

$$
S_{2 f}=\left(X_{2 f}^{2}+Y_{2 f}^{2}\right)^{1 / 2}=\frac{\eta G \overline{I_{0}}}{2}\left\{\left[H_{2}+\frac{i_{1}}{2}\left(H_{1}+H_{3}\right) \cos \psi_{1}\right]^{2}+\left[\frac{i_{1}}{2}\left(H_{1}-H_{3}\right) \sin \psi_{1}\right]^{2}\right\}^{1 / 2}
$$

where $G$ is the optical-electrical gain of the detection system. Since the measured gas is under standard atmospheric pressure, the broadening of the absorption spectrum shows a Lorentzian profile. The Fourier series of the Lorentz profile is an even harmonic function which means the amplitude of the odd harmonic component is zero [25,26]. So, Equation (8) will be simplified to:

$$
S_{2 f}=\frac{\eta G \overline{I_{0}}}{2} H_{2}
$$

In the same way, the equation of the first harmonic is given by:

$$
S_{1 f}=\left(X_{1 f}^{2}+Y_{1 f}^{2}\right)^{1 / 2}=\frac{\eta G \overline{I_{0}}}{2}\left\{\left[H_{1}+i_{1}\left(1+H_{0}+\frac{H_{2}}{2}\right) \cos \psi_{1}\right]^{2}+\left[i_{1}\left(1+H_{0}-\frac{H_{2}}{2}\right) \sin \psi_{1}\right]^{2}\right\}^{1 / 2}
$$

where $H_{1}=0$, and for low concentration gas, $H_{0}, H_{2}<<1$, thus:

$$
\begin{gathered}
S_{1 f}=\frac{\eta G \overline{I_{0}}}{2} i_{1} \\
\frac{S_{2 f}}{S_{1 f}}=\frac{H_{2}}{i_{1}}
\end{gathered}
$$

It can be seen from Equation (12) that using $1 f$ signal to normalize $2 f$ signal can eliminate the influence of various interference on the remote sensing results, such as the change of target reflectivity, the change of detection distance, the temperature drift of the photoelectric diode, and the change of the output laser light intensity, which greatly improves the anti-interference performance. 


\section{2. $\mathrm{NH}_{3}$ Absorption Line Selection}

According to the HITRAN database, $\mathrm{H}_{2} \mathrm{O}$ and $\mathrm{CO}_{2}$ in the atmosphere are the main interferences to the $\mathrm{NH}_{3}$ absorption line. For the remote sensor system, although the absorption intensity of $\mathrm{NH}_{3}$ molecules at $1512 \mathrm{~nm}$ nearby is several orders of magnitude higher than that of $\mathrm{H}_{2} \mathrm{O}$ and $\mathrm{CO}_{2}$ molecules [27], affected by the detection distance, the integral concentration of $\mathrm{H}_{2} \mathrm{O}$ molecules through the entire remote sensing range is much higher than that of $\mathrm{NH}_{3}$ molecules. Figure 1a shows the absorption spectra of $\mathrm{NH}_{3}, \mathrm{H}_{2} \mathrm{O}$, and $\mathrm{CO}_{2}$ from $6550 \mathrm{~cm}^{-1}$ to $6650 \mathrm{~cm}^{-1}$ based on the HITRAN database. It is clearly shown that the absorption line at $6612.7 \mathrm{~cm}^{-1}$ is the strongest line of $\mathrm{NH}_{3}$ around the range and has no overlap with the absorption lines of $\mathrm{H}_{2} \mathrm{O}$ and $\mathrm{CO}_{2}$. Furthermore, it is a single-peak absorption line which satisfies the requirement of $2 f / 1 f$ WMS signal processing theory. So, the characteristic absorption line at $1512.2 \mathrm{~nm}$ (wavenumber $=6612.7 \mathrm{~cm}^{-1}$ ) is selected as the wavelength of the remote sensing laser. Figure $1 \mathrm{~b}$ shows the absorption intensity of $1000 \mathrm{ppm} \cdot \mathrm{m} \mathrm{NH} \mathrm{NH}_{3}, 600,000 \mathrm{ppm} \cdot \mathrm{m} \mathrm{H}_{2} \mathrm{O}$ and $18,000 \mathrm{ppm} \cdot \mathrm{m} \mathrm{CO} \mathrm{CO}_{2}$ which are integral concentrations under the typical remote sensing distance of $30 \mathrm{~m}$ based on the HITRAN database. According to the data in Figure $1 b$, the absorption intensity of $\mathrm{H}_{2} \mathrm{O}$ and $\mathrm{CO}_{2}$ is much lower than that of $\mathrm{NH}_{3}$. Thus, the absorption intensity of $\mathrm{H}_{2} \mathrm{O}$ has no effect on the $\mathrm{NH}_{3}$ sensing results. Considering the absorption line of $\mathrm{H}_{2} \mathrm{O}$ at $6612 \mathrm{~cm}^{-1}$ interfering to the characteristic absorption line of $\mathrm{NH}_{3}$ at $6612.7 \mathrm{~cm}^{-1}$, the traditional "triangular wave + sine-wave" WMS scheme is abandoned and the "wavelength lock" scheme is adopted instead. This scheme is to fix the static output wavelength of a distributed feedback (DFB) laser at the center frequency and just modulate the output wavelength with a sinewave signal, which not only increases the sampling frequency, but also eliminates the interference of the $\mathrm{H}_{2} \mathrm{O}$ absorption line on the detection results.

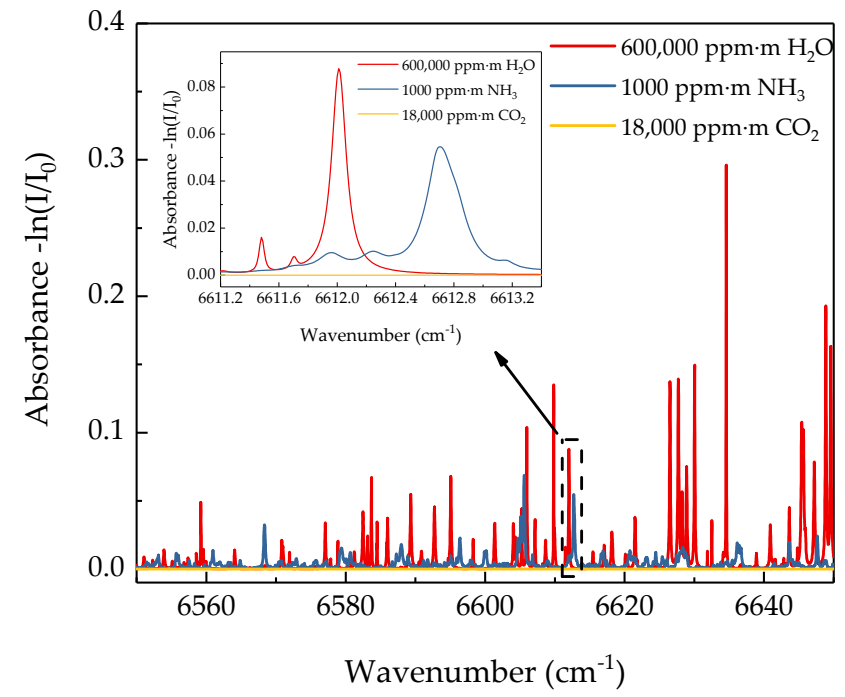

(a)

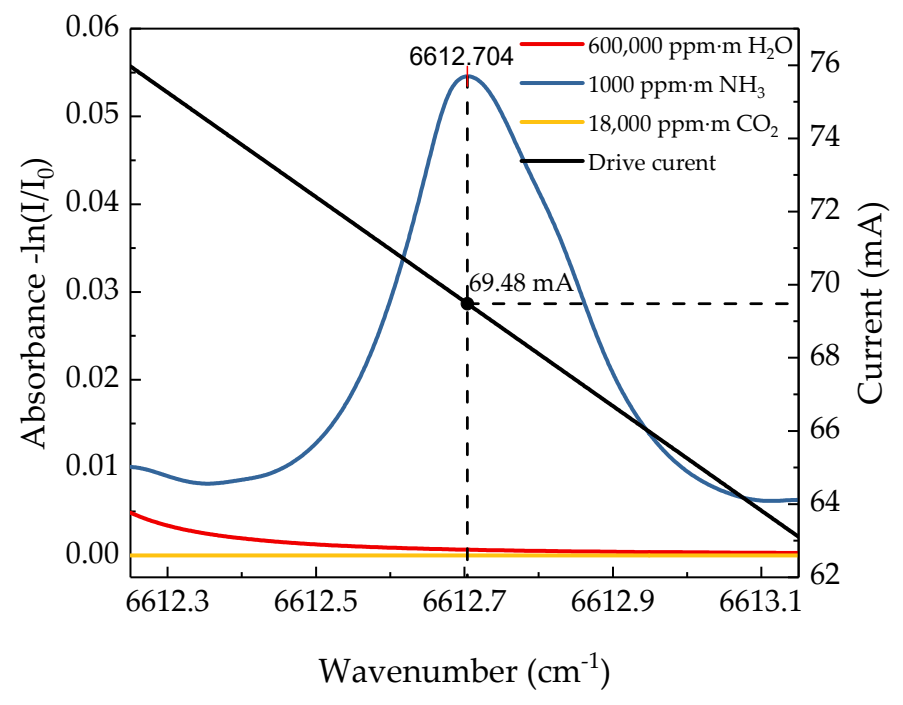

(b)

Figure 1. (a) Absorption spectra of $\mathrm{NH}_{3}, \mathrm{H}_{2} \mathrm{O}, \mathrm{CO}_{2}$ from $6550 \mathrm{~cm}^{-1}$ to $6650 \mathrm{~cm}^{-1}$. (b) Absorption spectra of $\mathrm{NH}_{3}$ (1000 ppm $\cdot \mathrm{m}$, blue line), $\mathrm{H}_{2} \mathrm{O}\left(1 \%\right.$, red line), and $\mathrm{CO}_{2}(0.03 \%$, yellow line) at an optical path of $60 \mathrm{~m}$ based on HITRAN database and the plot of drive current versus wavenumber of the distributed feedback (DFB) laser (black line), the value of modulation current at the central wavenumber $6612.7 \mathrm{~cm}^{-1}$ is $69.48 \mathrm{~mA}$.

\subsection{Output Characterization of DFB Laser and Wavelength-Locked Technique}

After the absorption line was selected, we chose a distributed feedback (DFB) laser at 1512.25 nm (Model: BF14, Sichuan Tengzhong light technology co., LTD, Mianyang, China) as the remote sensing laser source. A Fourier-transform infrared spectrometer (FTIR Spectrometer) was used to measure the characteristic parameters of the laser at different temperature and drive currents, the result is shown in Figure 2. The output wavelength 
of the laser is $1512.2 \mathrm{~nm}\left(6612.7 \mathrm{~cm}^{-1}\right)$ at $32{ }^{\circ} \mathrm{C}$ when the drive current is around $70 \mathrm{~mA}$. After linear fitting at this temperature, the current modulation coefficient of the DFB laser is obtained as $0.0141 \mathrm{~nm} / \mathrm{mA}$. The black line in Figure $1 \mathrm{~b}$ shows the change of modulation current within the range of wavelength modulation according to the test result of the DFB laser at $32{ }^{\circ} \mathrm{C}$. It can be seen from the figure that when the drive current is $69.48 \mathrm{~mA}$, the output wavelength is located at the center of the $\mathrm{NH}_{3}$ characteristic absorption line at $6612.7 \mathrm{~cm}^{-1}$. The output power of the laser is $11.28 \mathrm{~mW}$ at this point. Due to the interference of the $\mathrm{H}_{2} \mathrm{O}$ absorption line at $6612 \mathrm{~cm}^{-1}$, the modulation depth of the output wavelength should be less than $0.5 \mathrm{~cm}^{-1}$. Table 1 shows the characteristics of the selected laser. It should be noted that the characteristics are different between different laser devices and should be adjusted independently for measurement.

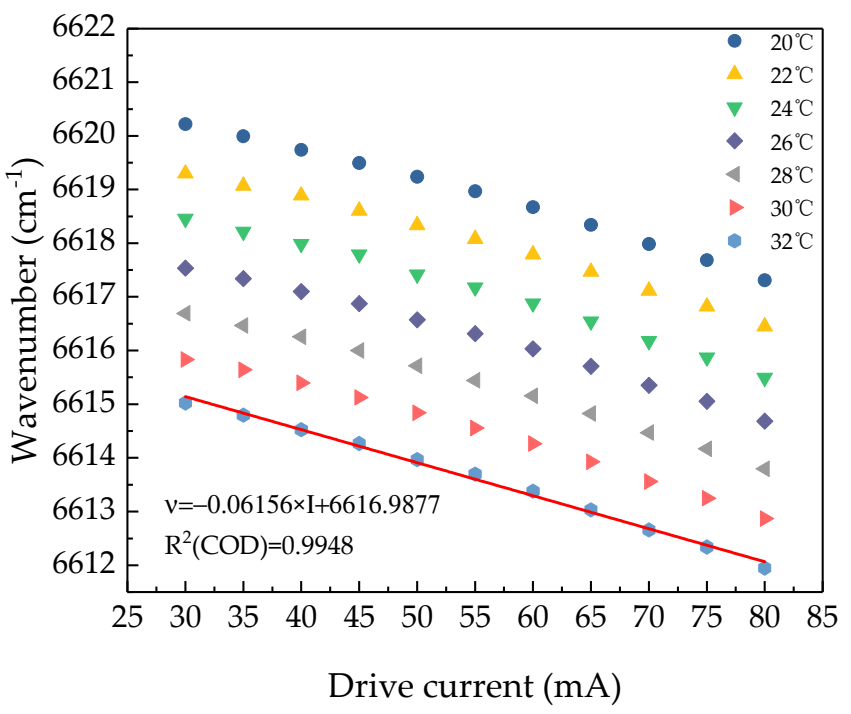

Figure 2. Output wavenumber of the DFB laser versus drive current at $20^{\circ} \mathrm{C}, 22{ }^{\circ} \mathrm{C}, 24^{\circ} \mathrm{C}, 26^{\circ} \mathrm{C}$, $28{ }^{\circ} \mathrm{C}, 30^{\circ} \mathrm{C}$, and $32{ }^{\circ} \mathrm{C}$. The red line is the linear fitting line of the selected temperature $\left(32^{\circ} \mathrm{C}\right)$. The slope of the fitting line is 0.06156 , which is the reciprocal of the slope of the black line shown in Figure $1 b$.

Table 1. The typical value and test value of the selected DFB laser characteristics.

\begin{tabular}{cccccc}
\hline Name & Unit & Min & $\begin{array}{c}\text { Typical } \\
\text { Value }\end{array}$ & Max & Test Data \\
\hline Threshold Current & $\mathrm{mA}$ & - & 10 & 18 & 9 \\
Output Power & $\mathrm{mW}$ & 10 & 12 & - & 11.28 \\
Operating Current & $\mathrm{mA}$ & - & 70 & 100 & 69.40 \\
Operating Voltage & $\mathrm{V}$ & - & 1.5 & 2 & 1.48 \\
Temperature & ${ }^{\circ} \mathrm{C}$ & 15 & 25 & 35 & 32 \\
Slope & $\mathrm{W} / \mathrm{A}$ & 0.05 & 0.1 & - & 0.1 \\
Peak Wavelength & $\mathrm{nm}$ & 1512.15 & 1512.25 & 1512.35 & 1512.24 \\
\hline
\end{tabular}

\subsection{Design of Remote Sensor System Structure}

Figure 3 shows the system structure of the remote sensor system. The system mainly includes three parts: the optical subsystem, the electrical subsystem, and the upper computer. The electrical subsystem is mainly composed of three parts: the main control module, the laser drive/temperature control module, and the signal amplifier module. The main control module is a self-made main control board based on DSP + ARM architecture processor. The functions of the main control board include the following: communicating with the upper computer through the RS- 485 protocol with a baud rate of 115,200; sending string instructions to the laser drive module to control it to generate a modulated current; sampling and quantizing the received signal by ADC on the board, the sampling 
frequency of which is $4 \mathrm{kHz}$; and supplying power to the system. The laser drive receives instructions from the main control module, and the DDS chip generates a sinusoidal drive current with a frequency of $128 \mathrm{~Hz}$. The temperature control circuit keeps the voltage of the thermistor packaged in the DFB laser at $1.48 \mathrm{~V}$ to stabilize the center wavelength of the laser at $1512.2 \mathrm{~nm}$. Because each laser is slightly different, the specific voltage and current values should be adjusted corresponding to different lasers.

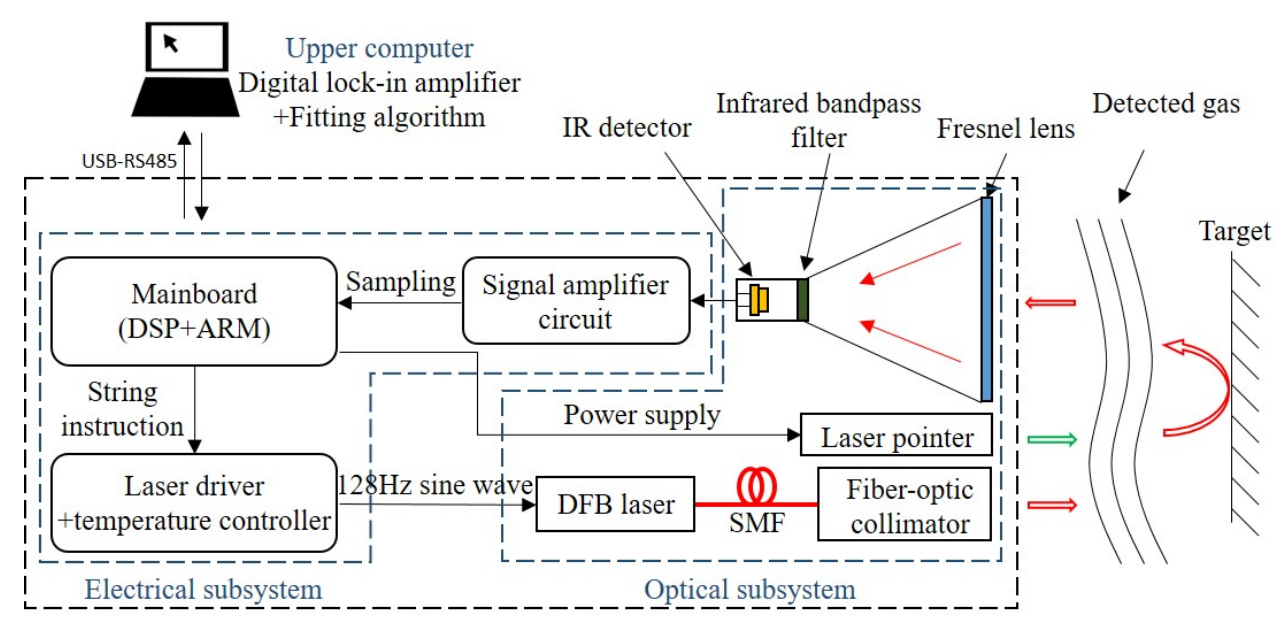

Figure 3. Schematic of the ammonia remote sensor system. This system consists of three parts: an optical subsystem, an electrical subsystem, and an upper computer.

The optical subsystem is mainly composed of a laser, an optical fiber collimator (CFC11A-C, Thorlabs), a laser pointer, and a signal-receiving module. The DFB laser has a center wavelength of $1512 \mathrm{~nm}$, which is connected to a collimator through a single-mode fiber (SMF) to generate a collimated laser beam. The collimator can adjust the emission direction of the laser and is fixed by reserved mounting seat to keep mechanical stability. This makes the optical path unchangeable when it encounters collision and vibration. Single-mode fiber has several merits in this application scenario; for example, low attenuation (about $0.2 \mathrm{db} / \mathrm{km}$ ) keeps the energy after the transmission; the low dispersion coefficient keeps the wave shape after the transmission; the narrow line width of the DFB laser is suitable to transfer in SMF $[20,28]$. The output laser beam should be adjusted to make it parallel to the beam of laser pointer (green light) during system debugging to make sure that the remote system can accurately align the measured gas during operation. The signal receiving module is composed of a Fresnel lens, an infrared filter, an infrared detector, and an amplifying circuit. The Fresnel lens $(\Phi=150 \mathrm{~mm}, f=140 \mathrm{~mm}$, profile pitch $=0.3 \mathrm{~mm}$ ) was used to receive the reflected light signal. To ensure the strength of the received signal, the profile pitch needs to be as narrow as possible with a fixed diameter of lens; furthermore, the focal length of the Fresnel lens needs to be as long as possible if it is within the acceptable range for the remote system. A longer focal length lens facilitates to adjust the optical path of the receiving module. The infrared detector is an InGaAs infrared photodiode (PGA10, Thorlabs), which is used to convert the received light signal into an electrical signal. Since the signal receiver receives all the optical signals with various wavelengths from the external environment, a band-pass infrared filter (FB1510-12, Thorlabs) is set up to filter out all the unexpected signal except the target wavelength. This reduces the influence of background noise on the telemetry results and improves the detection accuracy of the system.

The function of the upper computer is to process the telemetry data sent by the telemeter and display the result. A data processing platform developed based on LabVIEW runs on the upper computer to receive the remote sensing data. The platform is equipped with a digital lock-in algorithm, which can extract the first and second harmonics from the remote sensing signal. The second harmonic is normalized by the first harmonic and 
the calculation results are statistically averaged within a frame of data domain (4096 data points). At the same time, the data processing software can make a fitting on the calculation results. The fitting results are displayed through the front end. The advantages of using the upper computer to run the data processing software allow to avoid integrating the lock-in amplifier module and the display module into the system, which can greatly reduce the complexity of the system, and drops the R\&D cost and production cost of the system. Furthermore, the data processing software can run on any computer, which is convenient for the post debugging, modification, and function upgrade.

The remote sensor system we developed is highly integrated and cost-acceptable, which means it is more promising for improving productivity in commercial applications. All of the hardware was designed based on specific needs, including deleting an unnecessary module which miniaturized this system into a handheld instrument.

\section{Results and Discussion}

\subsection{Modulation Depth Optimization}

Typically, to obtain the maximum amplitude of the harmonic signal, the modulation depth should be 1.1 times greater than the full width at half maximum (FWHM) of the selected absorption line [29]. The method in the experiment is to adjust the resistor controlling the modulation current amplitude on the laser drive board to convert the modulation current amplitude into the corresponding modulation wavelength amplitude until finding the maximum of $2 f / 1 f$ signal calculated by the upper computer when measuring the gas sampling bag with the same integral concentration. The corresponding modulation wavelength amplitude of the resistor is the best modulation depth. In this experiment, a gas sampling bag with an integral concentration of $2000 \mathrm{ppm} \cdot \mathrm{m}$ was selected to optimize the modulation depth. During the experiment, the modulation amplitude of the drive current was selected to be $2.5-7.5 \mathrm{~mA}$, and the measured $2 f / 1 f$ signal amplitude is shown in Figure 4. When the amplitude of the drive current is $6 \mathrm{~mA}$ (modulation depth is $0.4199 \mathrm{~cm}^{-1}$ ), the $2 f / 1 f$ signal amplitude reaches the maximum. The modulation depth is 1.52 times greater than the FWHM of the $\mathrm{NH}_{3}$ absorption line.

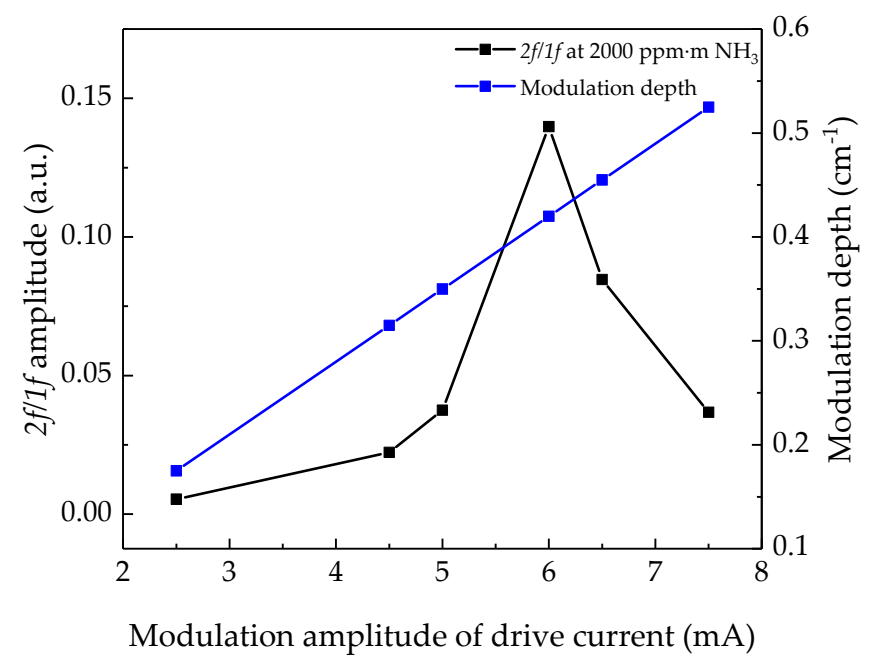

Figure 4. Modulation depth optimization performed at $2000 \mathrm{ppm} \cdot \mathrm{m} \mathrm{NH}_{3}$, the optimal modulation depth is $0.4199 \mathrm{~cm}^{-1}$ with a modulation amplitude of drive current at $6 \mathrm{~mA}$.

\subsection{Calibration of the $\mathrm{NH}_{3}$ Remote Sensor System}

According to the theory and practical test of the remote system, it can be known that the amplitude of $2 f / 1 f$ signal is proportional to the integral concentration of the measured gas. To facilitate the operation of testers, the system needs to be calibrated for concentration measurement. In this experiment, the $\mathrm{NH}_{3}$ remote sensor was calibrated by a series of gas sampling bags (the material is Teflon [13]), with an integral concentration range from 
$0 \mathrm{ppm} \cdot \mathrm{m}$ to $2000 \mathrm{ppm} \cdot \mathrm{m}$, and the target was a wall. The results obtained are shown in Figure $5 \mathrm{a}$, the standard deviation of the result at $0 \mathrm{ppm} \cdot \mathrm{m}$ is $4.85 \times 10^{-4} \mathrm{ppm} \cdot \mathrm{m}$, and the standard deviation of the result at 200-2000 ppm.m is between $1.90 \times 10^{-3}$ and $3.56 \times 10^{-3} \mathrm{ppm} \cdot \mathrm{m}$. This was caused by the vibration of the air bag and the optical path of the air bag could not be controlled sufficiently uniformly during measurement. The integral concentration value was plotted as a function of the $2 \mathrm{f} / \mathrm{f} f$ signal with error band of $2 \mathrm{f} / \mathrm{If}$ as shown in Figure $5 \mathrm{~b}$. The linear fitting of the data point was obtained as:

$$
C=15322.9872(2 f / 1 f)-80.3227
$$

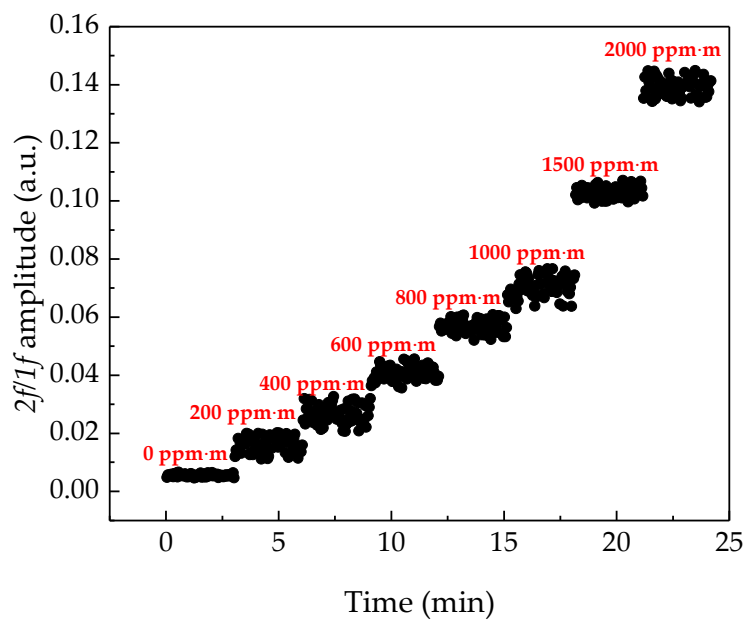

(a)

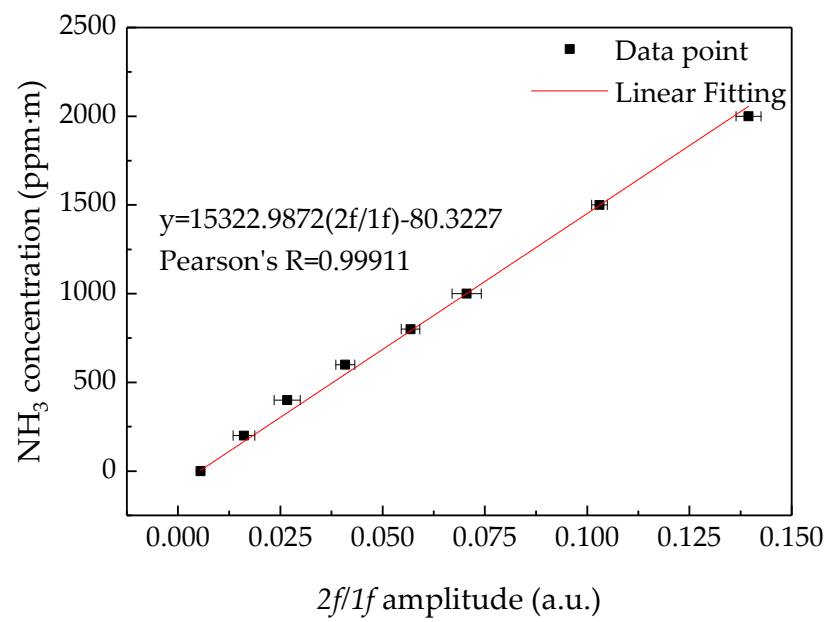

(b)

Figure 5. (a) Calibration of system by using a gas sampling bag with integral concentration from $0 \mathrm{ppm} \cdot \mathrm{m}$ to $2000 \mathrm{ppm} \cdot \mathrm{m}$, each concentration level was measured and recorded for about $3 \mathrm{~min}$. (b) Measured data dots and linear fitting curve of the $\mathrm{NH}_{3}$ integral concentration versus $2 f / 1 f$ signal amplitude.

The linear correlation coefficient is 0.99911 , which indicates that the $2 f / 1 f$ signal has an excellent linear relationship with the integral concentration of gas. Note that the fluctuation at $0 \mathrm{ppm} \cdot \mathrm{m}$ level is significantly weaker than others. The system was calibrated by using gas sampling bags; when measuring the signal amplitude of the integral concentration of $0 \mathrm{ppm} \cdot \mathrm{m}$, we filled the bag with nitrogen $\left(\mathrm{N}_{2}\right)$. This meant it could be less affected by the external environment. For example, when measuring gas sampling bags with other integral concentrations, a tiny incident angle change of infrared laser beam could make the optical path length of the bag change, which caused larger fluctuation in the measurement results. However, the $0 \mathrm{ppm} \cdot \mathrm{m}$ bag could not be changed in this situation.

\subsection{The Effect of $2 \mathrm{f} / 1 \mathrm{f}$ Signal Processing Technique on Sensing Results}

Traditional TDLAS based sensor system usually use the second harmonic of the absorption signal to characterize the concentration of the measured gas, while the $\mathrm{NH}_{3}$ remote sensor system uses the first harmonic to normalize the second harmonic to reduce the interference of signal strength on remote sensing results. To verify the effect of the $2 f / 1 f$ signal processing technique on noise suppression, the amplitudes of the $1 f$ signal, $2 f$ signal and the $2 f / 1 f$ signal measured with the same gas sampling bag under different distances were recorded. The experiment was carried out in the corridor inside the building, the target was a wall, and the integral concentration of the gas sampling bag was $2000 \mathrm{ppm} \cdot \mathrm{m}$. During the experiment, the gas sampling bag was fixed at one end of the corridor, and the $\mathrm{NH}_{3}$ remote sensor system was placed on a movable cart at the other end of the corridor and the distance between the two ends was about $50 \mathrm{~m}$. Pushing the cart to change the detection distance, the amplitudes of the $1 f$ signal, $2 f$ signal, and $2 f / 1 f$ signal were recorded by the $\mathrm{NH}_{3}$ remote sensor system at $50 \mathrm{~m}, 40 \mathrm{~m}, 30 \mathrm{~m}, 20 \mathrm{~m}, 10 \mathrm{~m}$. The measurement time for each distance was $5 \mathrm{~min}$; the measurement results are shown in Figure 6. It can be seen from the 
figure that the $1 f$ signal is sensitive to the change of the distance. With the increase of the distance, the amplitude of the $1 f$ signal keeps decreasing significantly, and the amplitude of the $2 f$ signal slightly changes during the entire process of the detection. However, the normalized $2 f / 1 f$ signal does not change significantly during the entire experiment, and the theoretical and experimental results are well verified.

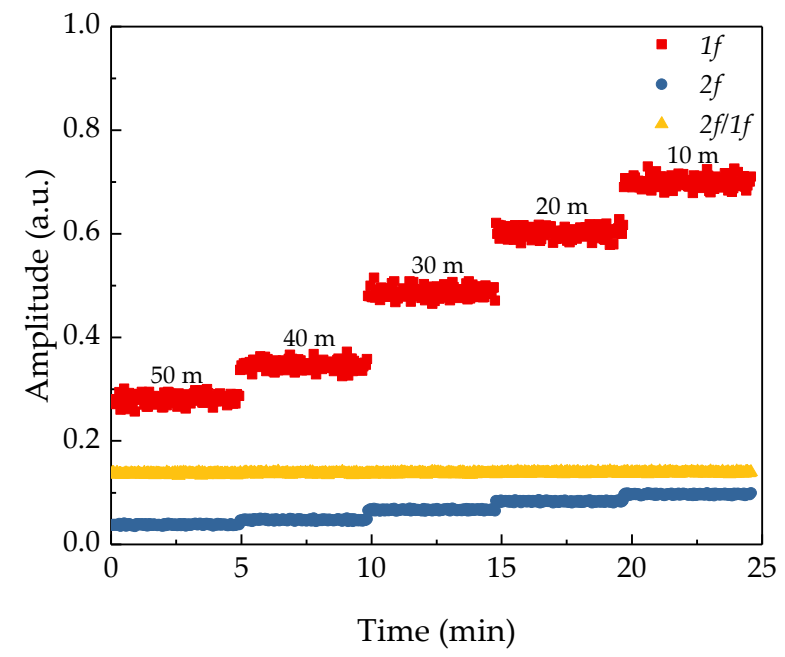

Figure 6. The change trend of the first harmonic, second harmonic, and the $2 f / 1 f$ signal of the absorbed signal versus the remote sensing distance.

\subsection{System Stability and Allan Deviation}

Allan deviation is an important tool to characterize the stability of the system. The lower limit of detection $(\mathrm{LoD})$ of the system and the influence of noise on system accuracy can be obtained through Allan deviation analysis. The sampling period of the $\mathrm{NH}_{3}$ remote sensor is $2.79 \mathrm{~s}$. The experiment measured the change of the $\mathrm{NH}_{3}$ concentration in the corridor of the building within $1 \mathrm{~h}$. The signal amplitude detected by the system was converted to concentration via Equation (12). The results are shown in Figure 7a. As shown in the figure, the results fluctuate around $50 \mathrm{ppm} \cdot \mathrm{m}$. The fluctuation is caused by the background noise generated by the internal noise of the system and the change of the external environment, and the influence of the white noise component can be suppressed by averaging the results in the time domain. The Allan deviation reflects the fluctuation of the measurement result with the extension of the averaging time. Figure $7 \mathrm{~b}$ shows the relationship between Allan deviation and the averaging time $\tau$. When the averaging time is $2.79 \mathrm{~s}$, the $1 \sigma \mathrm{LoD}$ is $16.6 \mathrm{ppm} \cdot \mathrm{m}$, and when the averaging time is $778.41 \mathrm{~s}$, the $1 \sigma \mathrm{LoD}$ of the system reaches a minimum of $0.46 \mathrm{ppm} \cdot \mathrm{m}$. At the same time, when the averaging time is within $700 \mathrm{~s}$, the trend of the Allan deviation decreasing is basically the same as $1 / \sqrt{\tau}$, which indicates that Johnson noise is dominant in the sensing results at this time. When the averaging time reaches $700 \mathrm{~s}$, increasing the averaging time cannot further improve the detection accuracy. At this time, the wavelength fluctuation noise is the main interference [30-32]. 


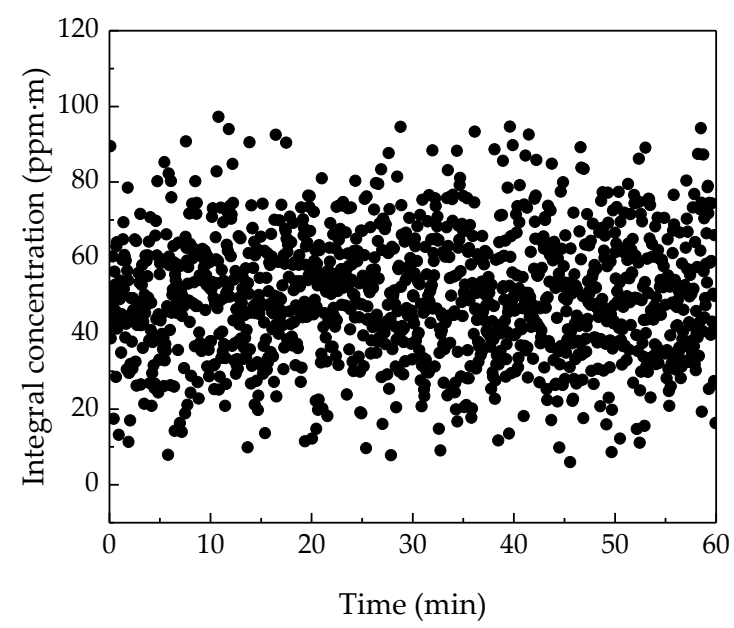

(a)

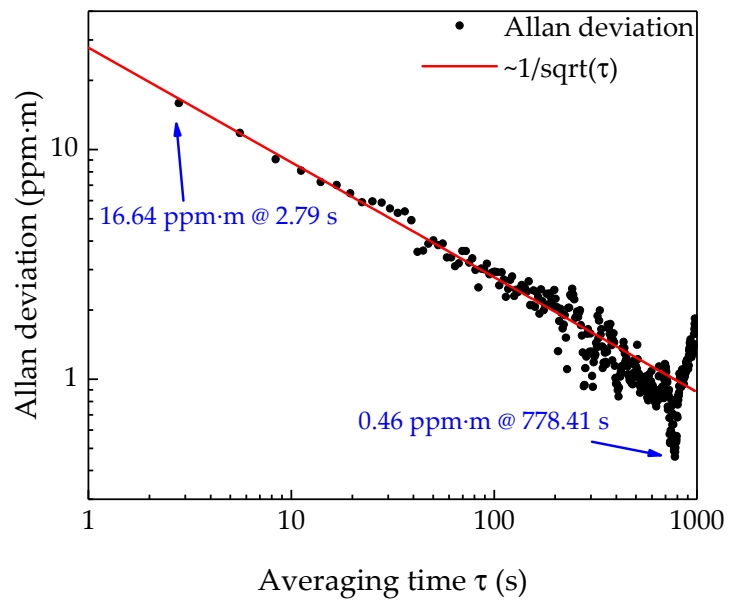

(b)

Figure 7. (a) The stability test of the remote sensor system for $1 \mathrm{~h}$ in the corridor of the building. (b) Allan deviation analysis of the sensor based on the stability test data shown in (a).

By further analysis of the test results we can find that the $\mathrm{NH}_{3}$ concentration detected in the corridor is about $50 \mathrm{ppm} \cdot \mathrm{m}$, which is a little higher than the normal $\mathrm{NH}_{3}$ concentration in air. Three potential $\mathrm{NH}_{3}$ sources in the corridor could cause this phenomenon: the toilet located in the corridor; the construction materials prepared for renovation of our college building; some organic synthesis experiments conducted in other laboratories in this building. Apart from these, this phenomenon is due to the system calibration. We can easily find out from Figure $5 b$ that the linear fitting line of calibration experiment does not pass through the zero-zero point of the coordinate, which means a measuring result of zero cannot be obtained by using this fitting expression when the $\mathrm{NH}_{3}$ concentration is close to $0 \mathrm{ppm} \cdot \mathrm{m}$. In other words, this is not the best working range of the system. However, this deviation does not affect the application of the system, because this system is used to detect whether the $\mathrm{NH}_{3}$ concentration is beyond the national safety standard or not, which is $40 \mathrm{ppm}$ for China. In this experiment, we only focus on the fluctuation of measuring result, which can characterize the stability of the system.

\subsection{Response Time}

The main factor that restricts the response time of the system is the communication rate between the sensor and the host computer. The serial port communication baud rate is 115,200 to send data to the computer. Each frame of data consists of 4096 32-bit floating point data points, including 128 modulation signal cycles. Theoretically, it takes $1.28 \mathrm{~s}$ to send one frame of data. Each frame of data is processed through a digital lock-in amplifier to extract the harmonic amplitude, remove the data points affected by the Fourier transform boundary conditions in the harmonic amplitude, and perform arithmetic average on the remaining 3584 data points and performs parameter fitting to generate a final telemetry result. In the practical test situation, a total of 1289 data points were obtained in $1 \mathrm{~h}$ of test time. Therefore, the data refresh time of the sensor is $2.79 \mathrm{~s}$. This response time is based on the "wavelength lock" scheme. If we adopted the traditional "triangular wave + sine-wave" scheme of TDLAS, the drive current would be modulated by, for example, $10 \mathrm{~Hz}$ triangle wave and $1 \mathrm{kHz}$ sine wave, which means the sensor system can only scan 20 times per second. Compared to our scheme, the wavelength-lock mode can achieve a 6 times faster refresh rate. At the same time, this scheme has a higher requirement for the temperature stability of the system to avoid wavelength drift. The limit factor for improving response time is the communication rate. If we integrate the lock-in amplifier module in the system and transfer the harmonic signal to the computer directly, this limitation can be overcome. 


\subsection{Simulated Application}

The calibrated and debugged ammonia remote sensing system was tested outdoors for $\mathrm{NH}_{3}$ leakage under simulated conditions. The test environment is shown in Figure 8a. During the experiment, $\mathrm{NH}_{3}$ cylinders with concentrations of 50,000 ppm, 10,000 ppm, and $2000 \mathrm{ppm}$ were placed from left to right at a distance of $25 \mathrm{~m}$. The target was a painted steel plate at a distance of $30 \mathrm{~m}$ from the remote sensor system. The $\mathrm{NH}_{3}$ cylinder was opened during the test to simulate the $\mathrm{NH}_{3}$ leakage under industrial conditions, and the indicating laser of the remote sensor system was targeted at the $\mathrm{NH}_{3}$ leakage port, so that the system subsequently measured the $\mathrm{NH}_{3}$ concentration at the three leakage sources; the measurement time was about $2 \mathrm{~min} 30 \mathrm{~s}$. When we finished the measurement of one leakage source, we pushed the platform to the next leakage port and targeted it vertically to keep the distance unchanged. Figure $8 \mathrm{~b}$ shows the $\mathrm{NH}_{3}$ concentration of the three leakage sources measured by the system, the order of the measurement was from right to left. It can be seen from the figure that there are obvious differences in the concentration between different leakage sources. The system placed on the ground contains a lead-acid battery, an inverter, and a stabilized power supply, which simulates vehicle power supply. This experiment shows that the ammonia sensor has good practicability.

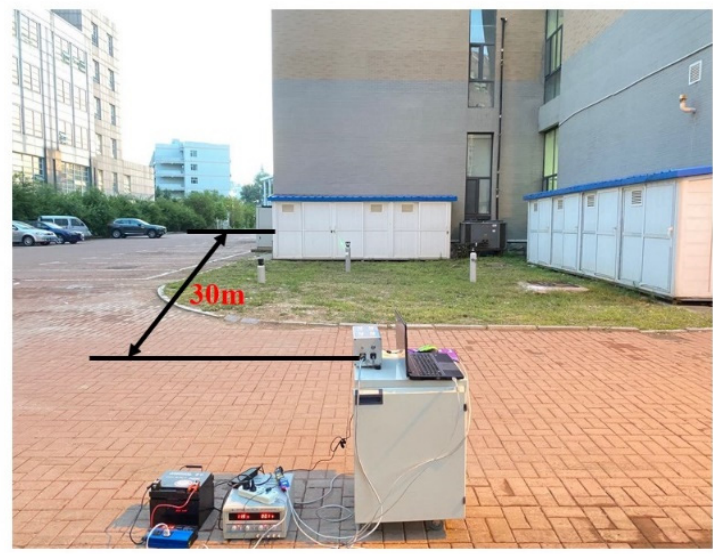

(a)

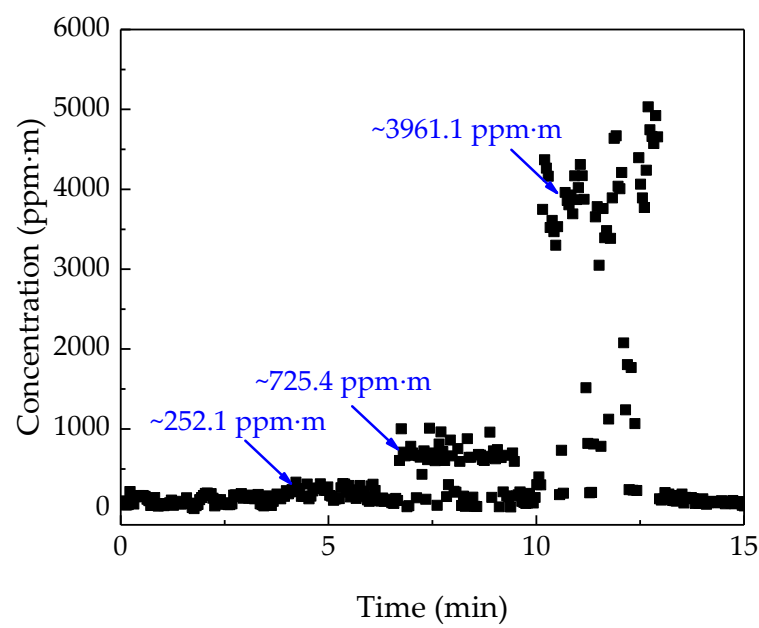

(b)

Figure 8. (a) The outdoor experiment where $\mathrm{NH}_{3}$ gas cylinders were set at a distance of $25 \mathrm{~m}$ to simulate industrial $\mathrm{NH}_{3}$ leakage; the concentration order from right to left is $2000 \mathrm{ppm}, 10,000 \mathrm{ppm}, 50,000 \mathrm{ppm}$; and the distance from target is 30 m. (b) The integral concentration of $\mathrm{NH}_{3}$ at the three leakage ports obtained by the $\mathrm{NH}_{3}$ remote sensor system based on the test conditions shown in (a).

To analyze the precision of the system, we simulated the spatial distribution of the $\mathrm{NH}_{3}$ concentration under the no-wind condition based on MATLAB by use of the gas turbulence diffusion model. Figure 9 a shows the horizontal distribution of $\mathrm{NH}_{3}$ concentration $0.2 \mathrm{~m}$ above the leakage source, and Figure $9 \mathrm{~b}$ shows the vertical distribution of $\mathrm{NH}_{3}$ concentration at the leakage source. The concentration of leakage source is $10,000 \mathrm{ppm}$, and the flow rate is $0.05 \mathrm{~L} / \mathrm{s}$, which is close to the actual situation. The integral concentration of $\mathrm{NH}_{3}$ at $0.2 \mathrm{~m}$ above the leakage source is $995 \mathrm{ppm} \cdot \mathrm{m}$ according to the simulated result. The tested stable value is $725.4 \mathrm{ppm} \cdot \mathrm{m}$ in the experiment. Considering the environmental influence on the experiment, the measurement result is consistent with the theoretical diffusion model, indicating that the remote sensor system has satisfactory precision. 


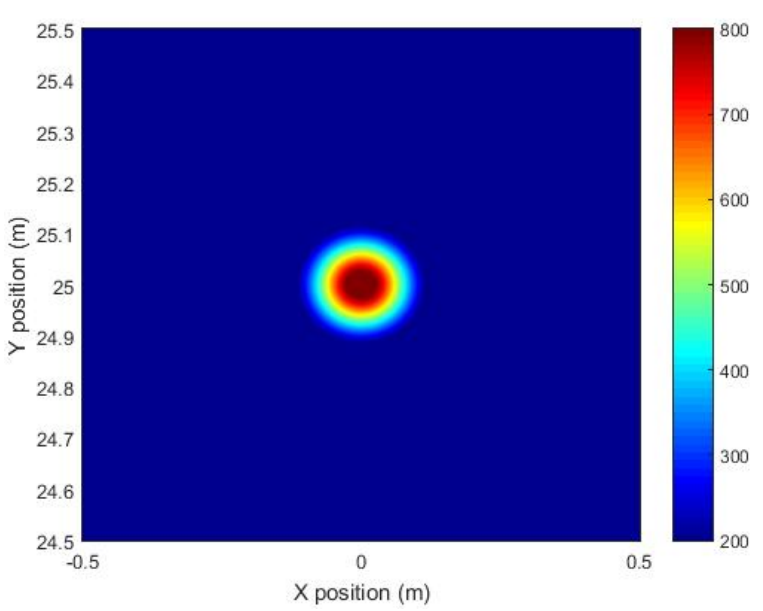

(a)

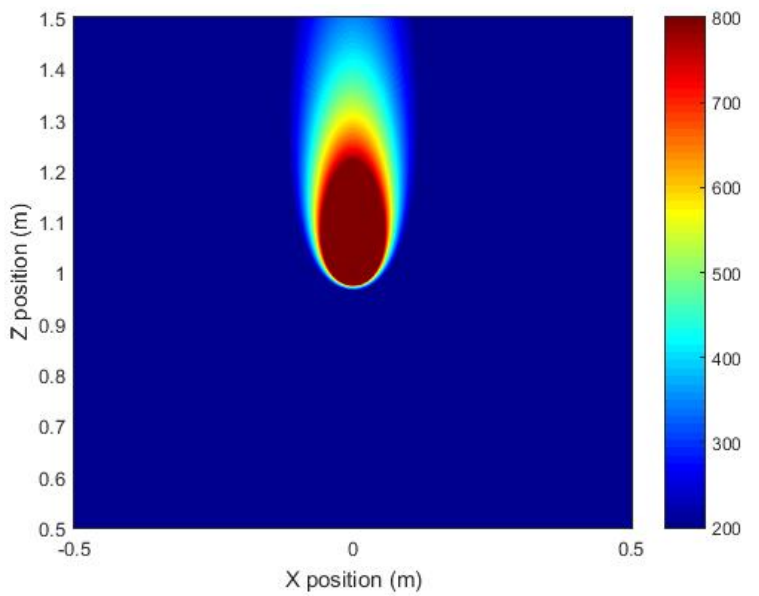

(b)

Figure 9. (a) The horizontal distribution of $\mathrm{NH}_{3}$ concentration $0.2 \mathrm{~m}$ above the leakage source. (b) The vertical distribution of $\mathrm{NH}_{3}$ concentration at the leakage source.

\section{Conclusions}

This paper introduced a $\mathrm{NH}_{3}$ remote sensor system based on the TDLAS technique. To solve the problems caused by the target reflectivity and light intensity change during remote sensing, the $2 f / 1 f$ signal processing technique and its mathematical principles were introduced. According to the drive characteristics of the laser, the static output is stabilized at $6612.7 \mathrm{~cm}^{-1}$ by controlling the temperature and the driving current. Based on the modulation depth optimization and concentration calibration, the effect of the $2 f / 1 f$ signal processing technique on the remote sensing results under practical test conditions were presented. The results showed that the $2 f / 1 f$ signal processing technique has a good inhibitory effect on the fluctuation of the remote detection results. Allan deviation analysis was used to characterize the stability of the system. It was concluded that when the averaging time was $2.79 \mathrm{~s}$, the $1 \sigma \mathrm{LoD}$ of the system was $16.6 \mathrm{ppm} \cdot \mathrm{m}$, and when the average time was $778.41 \mathrm{~s}$, the $1 \sigma \mathrm{LoD}$ of the system reached a minimum of $0.46 \mathrm{ppm} \cdot \mathrm{m}$. The detection limit met Chinese safety standard for indoor $\mathrm{NH}_{3}$ concentration of $40 \mathrm{ppm}$. The response time of the system was measured to be $2.79 \mathrm{~s}$. Three $\mathrm{NH}_{3}$ cylinders were used to simulate the leakage source to carry out an experiment of leakage measurement under outdoor conditions, and satisfactory remote sensing results were obtained.

Author Contributions: Conceptualization, H.L. and Z.L.; methodology, H.L.; software, L.Z.; validation, Y.Z., and F.S.; formal analysis, X.L.; resources, Y.W.; data curation, H.L.; writing-original draft preparation, H.L.; writing-review and editing, C.Z.; supervision, C.Z.; project administration, C.Z.; funding acquisition, Y.W. All authors have read and agreed to the published version of the manuscript.

Funding: This research was funded by the National Key R\&D Program of China (No. 2017YFB0405300), National Natural Science Foundation of China (Nos. 61775079, 61627823, 61960206004), Science and Technology Development Program of Jilin Province, China (Nos. 20180201046GX, 20190101016JH, 20200401059GX).

Institutional Review Board Statement: Not applicable.

Informed Consent Statement: Not applicable.

Data Availability Statement: Not applicable.

Conflicts of Interest: The authors declare no conflict of interest. 


\section{References}

1. Li, S.W.; Chang, M.H.; Li, H.M.; Cui, X.Y.; Ma, L.Q. Chemical compositions and source apportionment of PM2.5 during clear and hazy days: Seasonal changes and impacts of Youth Summer Olympic Games. Chemosphere 2020, 256, 127163. [CrossRef]

2. Wang, P.; Cao, J.-J.; Shen, Z.-X.; Han, Y.-M.; Lee, S.-C.; Huang, Y.; Zhu, C.-S.; Wang, Q.-Y.; Xu, H.-M.; Huang, R.-J. Spatial and seasonal variations of PM 2.5 mass and species during 2010 in Xi'an, China. Sci. Total Environ. 2015, 508, 477-487. [CrossRef] [PubMed]

3. Kong, L.; Tang, X.; Zhu, J.; Wang, Z.; Pan, Y.; Wu, H.; Wu, L.; Wu, Q.; He, Y.; Tian, S.; et al. Improved Inversion of Monthly Ammonia Emissions in China Based on the Chinese Ammonia Monitoring Network and Ensemble Kalman Filter. Environ. Sci. Technol. 2019, 53, 12529-12538. [CrossRef] [PubMed]

4. Hodgkinson, J.; Tatam, R.P. Optical gas sensing: A review. Meas. Sci. Technol. 2012, 24, 012004. [CrossRef]

5. Guth, U.; Vonau, W.; Zosel, J. Recent developments in electrochemical sensor application and technology-A review. Meas. Sci. Technol. 2009, 20, 91. [CrossRef]

6. Kwak, D.; Lei, Y.; Maric, R. Ammonia gas sensors: A comprehensive review. Talanta 2019, 204, 713-730. [CrossRef] [PubMed]

7. Salem, A.A.; Soliman, A.A.; El-Haty, I.A. Determination of nitrogen dioxide, sulfur dioxide, ozone, and ammonia in ambient air using the passive sampling method associated with ion chromatographic and potentiometric analyses. Air Qual. Atmos. Health 2009, 2, 133-145. [CrossRef]

8. Miller, D.J.; Sun, K.; Tao, L.; Khan, M.A.; Zondlo, M.A. Open-path, quantum cascade-laser-based sensor for high-resolution atmospheric ammonia measurements. Atmos. Meas. Tech. 2014, 7, 81-93. [CrossRef]

9. He, Y.; Jin, C.; Kan, R.; Liu, J.; Liu, W.; Hill, J.; Jamie, I.M.; Orr, B.J. Remote open-path cavity-ringdown spectroscopic sensing of trace gases in air, based on distributed passive sensors linked by km-long optical fibers. Opt. Express 2014, 22, 13170-13189. [CrossRef]

10. Tao, L.; Sun, K.; Miller, D.J.; Pan, D.; Golston, L.M.; Zondlo, M.A. Low-power, open-path mobile sensing platform for highresolution measurements of greenhouse gases and air pollutants. Appl. Phys. A 2015, 119, 153-164. [CrossRef]

11. Guo, X.; Zheng, F.; Li, C.; Yang, X.; Li, N.; Liu, S.; Wei, J.; Qiu, X.; He, Q. A portable sensor for in-situ measurement of ammonia based on near-infrared laser absorption spectroscopy. Opt. Lasers Eng. 2019, 115, 243-248. [CrossRef]

12. Vasileiadis, M.; Athanasekos, L.; Meristoudi, A.; Alexandropoulos, D.; Mousdis, G.; Karoutsos, V.; Botsialas, A.; Vainos, N.A. Diffractive optic sensor for remote-point detection of ammonia. Opt. Lett. 2010, 35, 1476-1478. [CrossRef]

13. Force, A.P.; Killinger, D.K.; Defeo, W.E.; Menyuk, N. Laser remote sensing of atmospheric ammonia using a CO_2 lidar system. Appl. Opt. 1985, 24, 2837-2841. [CrossRef]

14. Thériault, J.; Puckrin, E. Remote sensing of chemical vapours by differential FTIR radiometry. Int. J. Remote. Sens. 2005, 26, 981-995. [CrossRef]

15. Dammers, E.; Vigouroux, C.; Palm, M.; Mahieu, E.; Warneke, T.; Smale, D.; Langerock, B.; Franco, B.D.G.M.; Van Damme, M.; Schaap, M.G.; et al. Retrieval of ammonia from ground-based FTIR solar spectra. Atmos. Chem. Phys. Discuss. 2015, 15, 12789-12803. [CrossRef]

16. Dammers, E.; Palm, M.; Damme, M.V.; Vigouroux, C.; Smale, D.; Conway, S.; Toon, G.C.; Jones, N.; Nussbaumer, E.; Warneke, T.; et al. An evaluation of IASI-NH3 with ground-based FTIR measurements. Atmos. Chem. Phys. 2016, 16, 1-30. [CrossRef]

17. Dammers, E.; Schaap, M.; Haaima, M.; Palm, M.; Kruit, R.J.W.; Volten, H.; Hensen, A.; Swart, D.; Erisman, J.W. Measuring atmospheric ammonia with remote sensing campaign: Part $1-$ Characterisation of vertical ammonia concentration profile in the centre of The Netherlands. Atmos. Environ. 2017, 169, 97-112. [CrossRef]

18. Malka, D.; Berkovic, G.; Hammer, Y.; Zalevsky, Z. Super-Resolved Raman Spectroscopy. Spectrosc. Lett. 2013, 46, 307-313. [CrossRef]

19. Pogány, A.; Balslev-Harder, D.; Braban, C.F.; Cassidy, N.; Ebert, V.; Ferracci, V.; Hieta, T.; Leuenberger, D.; Martin, N.A.; Pascale, C.; et al. A metrological approach to improve accuracy and reliability of ammonia measurements in ambient air. Meas. Sci. Technol. 2016, 27, 115012. [CrossRef]

20. Moshaev, V.; Leibin, Y.; Malka, D. Optimizations of Si PIN diode phase-shifter for controlling MZM quadrature bias point using SOI rib waveguide technology. Opt. Laser Technol. 2021, 138, 106844. [CrossRef]

21. Atkins, P.; Paula, J.D. Elements of Physical Chemistry, 5th ed.; Oxford University Press: New York, NY, USA, 2009 ; pp. 447-469.

22. Ozaki, Y.; Huck, C.W.; Beć, K.B. Near-IR Spectroscopy and Its Applications. Molecular and Laser Spectroscopy: Advances and Applications, 1st ed.; Gupta, V.P., Ed.; Elsevier: Amsterdam, The Netherlands, 2018; pp. 11-38.

23. Ding, W.W.; Sun, L.Q.; Yi, L.Y. High sensitive scheme for methane remote sensor based on tunable diode laser absorption spectroscopy. Acta Phys. Sin. 2017, 66, 100702.

24. Li, H.; Rieker, G.B.; Liu, X.; Jeffries, J.B.; Hanson, R.K. Extension of wavelength-modulation spectroscopy to large modulation depth for diode laser absorption measurements in high-pressure gases. Appl. Opt. 2006, 45, 1052-1061. [CrossRef] [PubMed]

25. Myers, O.E.; Putzer, E.J. Measurement Broadening in Magnetic Resonance. J. Appl. Phys. 1959, 30, 1987-1991. [CrossRef]

26. Arndt, R. Analytical Line Shapes for Lorentzian Signals Broadened by Modulation. J. Appl. Phys. 1965, 36, 2522. [CrossRef]

27. Modugno, G.; Corsi, C. Water vapour and carbon dioxide interference in the high sensitivity detection of $\mathrm{NH}_{3}$ with semiconductor diode lasers at $1.5 \mu \mathrm{m}$. Infrared Phys. Technol. 1999, 40, 93-99. [CrossRef]

28. Kasap, S.O. Optoelectronics \& Photonics: Principles E Practices, 2nd ed.; Pearson: Toms River, NJ, USA, 2012; pp. 71-94. 
29. Liu, Z.; Zheng, C.; Chen, C.; Li, Y.; Xie, H.; Ren, Q.; Wang, Y.; Tittel, F.K. ICL-based mid-infrared carbon dioxide sensor system for deep-sea natural gas hydrate exploration. Opt. Express 2019, 27, 5598-5609. [CrossRef] [PubMed]

30. Allan, D. Statistics of atomic frequency standards. Proc. IEEE 1966, 54, 221-230. [CrossRef]

31. Giglio, M.; Patimisco, P.; Sampaolo, A.; Scamarcio, G.; Tittel, F.K.; Spagnolo, V. Allan Deviation Plot as a Tool for Quartz-Enhanced Photoacoustic Sensors Noise Analysis. IEEE Trans. Ultrason. Ferroelectr. Freq. Control 2016, 63, 555-560. [CrossRef]

32. Zheng, K.; Zheng, C.; Yao, D.; Hu, L.; Liu, Z.; Li, J.; Zhang, Y.; Wang, Y.; Tittel, F.K. A near-infrared $\mathrm{C}_{2} \mathrm{H}_{2} / \mathrm{CH}_{4}$ dual-gas sensor system combining off-axis integrated-cavity output spectroscopy and frequency-division-multiplexing-based wavelength modulation spectroscopy. Analyst 2019, 144, 2003-2010. [CrossRef] 